\title{
An Excellent Omen
}

\begin{abstract}
Franco Gianturco, the Editor-in-Chief of Europhysics Letters, believes that the journal's first ten
\end{abstract} years are a good omen for the continuing success of this investment in a European future.

The idea of setting up a European journal comparable to Physical Review Letters published by the American Physical Society had been around for a some time back in the early-1980s. Some physicists felt that they would prefer their results to be published in Europe rather than elsewhere; others believed that the standard of refereeing and speed of publication for European papers submitted to Phys. Rev. Lett. were not to their complete satisfaction.

\section{An Idea Became a Vigorous Reality}

In addition to "short communications" in the Institute of Physics Journal of Physics, four mainstream physics letters journals were being published in Europe in the early 1980 s. However, they neither covered all areas of physics nor were they supported by authors from throughout Europe. Physics Letters A and Physics Letters $B$, both published by North Holland, were restricted to certain subfields. Of the two general letters journals, Journal de Physique Lettres published by Les Editions de Physique catered principally for French physicists while the other, Lettere al Nuovo Cimento published by the Italian Physical Society, although managing to attract international authors in some areas, was mainly supported by Italian physicists. Throughout the early 1980 s a group of physicists worked towards creating a European letters journal in physics, notably
Antonino Zichichi of Bologna on behalf of the Italian society, Philippe Nozières on behalf of the French Physical Society, Louis Michel (Les Editions de Physique), Roy Pike (Institute of Physics), Gert Eilenberger from Jülich, Josef Devreese from Antwerp and, on behalf of the European Physical Society, Ted Shaw and Jacques Friedel, who was the EPS President at the time. An excellent account of the fairly stressful events that led up to the launch of Europhysics Letters in January 1986 was given by Ted Shaw in the special issue of Europhysics News devoted to the 25th anniversary of EPS [EN 24 (1993) 149].

The launch took place under the auspices of 11 national societies (with the Scandinavian societies counting as a single unit) plus EPS. The partnership agreement was based on Journal de Physique Lettres and Lettere al Nuovo Cimento being absorbed into the new journal, which set to work with 12 carefully selected CoEditors who were experts in various areas of physics. Nicholas Kurti of Oxford received universal approval as the first Editor-in-Chief, and a further slate of around 30 Advisory Editors provided additional expertise and know-how when necessary.

With a refereeing procedure designed to ensure that no special patronage arose and strong encouragement from the CoEditors, the Advisory Editors and physicists throughout the various EPS Divi-

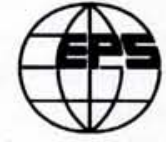

\section{European Physical Society} EurophysNet - http:/epswww.epfl.ch/ Published by Europhysics News to inform members. Editor: P.G. Boswell, EPS, BP 69, CH1213, Petit-Lancy 2 - peter.boswell@cern.ch $\mathrm{Tel}+41-22-7931130-\mathrm{Fax}+41-22-79313$

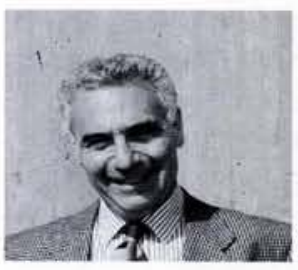

Franco Gianturco, the Editor-in-Chief of Europhysics Letters, is professor of chemical physics at the University of Rome "La Sapienza".

sions, contributions began to stream in. There was a flood of excellent articles within a very short time, with the number of manuscripts received in late-1985 and throughout 1986 totalling 900 - a very satisfactory number for a new journal.

Over the next ten years, Europhysics Letters grew in size and in circulation, throughout Europe and the rest of the world. In 1995, some 850 papers were received and of these about 430 were published - and the initial excitement has not subsided. The acceptance rate has been fairly steady at around 50\%. Rapid publication is an essential feature of a letters journal. The median time from receipt to acceptance of a manuscript without revisions is $81 / 2$ weeks, with publication occurring within a further 6-7 weeks.

Much More than a Promising Future

As physicists are well aware of the advantages of electronic publishing and the potential of the Internet, following

\section{Europhysics Letters}

Submissions to Europhysics Letters (EPL) should contain non-trivial new results, ideas, concepts, experimental methods, theoretical treatments, etc. and be of broad interest and importance to one or or more sections of the physics community. The presentation should satisfy the specialist, yet remain understandable to those working in other fields.

The original and three copies of a manuscript should be sent to Mrs. E. Thomas, Staff Editor, Europhysics Letters, P.O. Box 69, CH - 1213 Petit-Lancy 2. Alternatively, authors may send the original and two copies to the Staff Editor and one copy directly to the Co-Editor whom they believe would be responsible for their paper. The length of the manuscript should not exceed six journal pages ( 23500 equivalent characters, including formulae, figures, tables, and references but not title, authors' names and abstract).

When the EPL Editorial Office informs the principal author that the article has been accepted for publication,

authors are encouraged to send the matching electronic version together with PostScript files of figures to europhysics@sif.it. Word and plain text files are accepted, but unlike $T_{E} X$ and $L A T_{E} X$ files they need partial retyping. Detailed author's instructions are available from the Editions de Physique at http://www.ed_phys.fr/docinfos/OnlineEURO.html and at http://www.sif.it. A set of LAT $\mathrm{X}$ macros are available from the Editorial Office and by anonymous ftp at ftp.sif.it.

The basic subscription price for 1997 is CHF 1820.- p.a. comprising 4 volumes of 9 issues (airmail delivery to Australia, Canada, Japan, the USA and South America included). Orders to Les Editions de Physique, Ave. du Hoggar, Z.I. de Courtaboeuf, BP 112, F-91944 Les Ulis Cedex A (fax: +33-1-69 2884 91; info@ed-phys.fr).EPS Individual Ordinary Members enjoy a reduced basic subscription price of CHF 220.- (orders to EPS, Nádor u. 7, H-1051 Budapest). Personal subscription rates are also available to members of institutes having a full-price institutional subscription. All subscriptions include free-ofcharge access to the fully electronic on-line version.

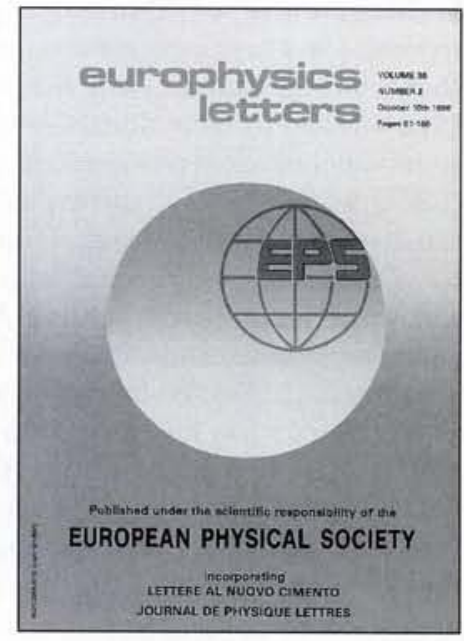


their acceptance, manuscripts can be emailed to the publisher as $\mathrm{T}_{\mathrm{E}} \mathrm{X}$ files, so proof correction creates minimal delay. Moreover, the titles and abstracts of papers to be published in Europhysics Letters are available at the publisher's WorldWide Web site to everyone with WWW access (the URL is http://www.ed-phys.fr/ docinfos/OnlineEURO.html); abstracts are incorporated into the CODAS alterting service. Subscribers to the printed edition can access an electronic version of the journal via WWW at no extra charge (some $20 \%$ have elected to take advantage of this offer since its launch last year).

One should remember that Europhysics Letters is a scientific endeavour run by physicists. Although run extremely professionally, it is essentially not a commercial operation, so many technical issues are approached for their scientific relevance rather than for their ability to increase income. Technical improvements might thus be expected to take longer than for a commercial enterprise. However, the speed and manner in which modern submission, production and publication procedures have been adopted shows that Europhysics Letters has been able to respond quickly and thoroughly. This augers well for the future.

All aspects of physics are represented in Europhysics Letters. However, by 1995 papers in condensed matter physics constituted about one-half of all the published material. The Editors would like to see other areas better represented, so colleagues are encouraged to think more often in European terms when choosing a journal to submit their work to.

So where do we go from here? As the fourth Editor-in-Chief, my primary concern is to enhance the commitment of my predecessors to the welfare of the journal. I also hope to increase the audience and to broaden the areas of physics which are represented. These aims are accomplished chiefly through contacts with the EPS Divisions and Interdivisional Groups, by attending their conferences and by urging colleagues to appreciate and exploit a firstrate scientific outlet for research results.

Europhysics Letters is still fairly young and our community changes its publishing habits rather reluctantly. However, I think a European publication belonging to all of us represents a way for everyone to invest in the future. So there is no other direction but ahead, and with more of us being involved. The first ten years have been a very good omen for predicting the success of this precious investment.

\section{TheEPSDivisions}

Individual Ordinary Members (IOMs) of EPS as well as members of National Member Societies which belong to EPS can join any number of EPS Divisions or Interdivisional Groups. IOMs need to inform the EPS Secretariat while National Society Members (NSMs) should contact a national society to which they belong. Arrangements are also being made to allow IOMs and NSMs join a Division by completing an appropriate form on the EPS EurophysNet WWW service (http//epswww.epfl.ch/). In the case of NSMs, the completed form is automatically emailed to a designated national society if the society is one of those that accepts registrations by email.

Summaries of the Divisions and their activities are given below to help assist members choose a Division and/or a Section within a Division. Many will no doubt appreciate that aside from coordinating and promoting technical specialities and organizing conferences and publications of all sorts, the Divisions and Section have many general activities. These include: providing independent expertise and advice upon request, as well as peer reviewers or referees for say the European Commission; proposing (in some cases organizing) European Research Conferences in Physics; proposing speakers for major EPS conferences such as the EPS General Conference; serving on editorial boards of publications; nominating an EPS Lecturer who makes open presentations across Europe; supporting measures to help physicists from the less-favoured regions of Europe participate in, and profit from, EPS initiatives. The summaries below indicate for each Division and Section: the number of members; the number of participants and the dates and places of the next Division or Section conferences. Summaries of the Interdivisional Groups will appear in the next issue of News from EPS.

\section{- Astrophysics Division (688)}

Chair: H.C.E. Huber, Space Science Dept., ESA-ESTEC, POB 299, NL-2200 AG Noordijk [+31-71-56535 52/ 5654699 ] mhuber@astro.estec.esa.nl.

Board: C. Chiuderi (Florence), A. de Rujula (CERN), M. Jacob (CERN), N. Kardashev (Moscow), G. Nugebauer (Jena), J. Perez-Mercader (Madrid). G. Simnett (Birmingham), J.P. Swings (Sec., Liège) G.A. Tamman (Basle).

A joint Division of the EPS and the European Astronomical Society: promotes collaboration between physics and astronomy. Members can be members of either EAS, EPS or both, or members of an EPS National Member Society. Reduced fee for individual membership of both EAS and EPS. Aims to participate actively in organizing EAS and EPS meetings, notably general conferences.

Solar Physics Section (SPS, 248) - Chair: G.M. Simnett (Birmingham). An association of European scientists engaged in or interested in any aspect of solar physics, including its relation to neighbouring disciplines. Conference: European Meeting on Solar Physics (triennial; 200 part.; 1999) in collaboration with CESRA and JOSO. Aims to organize parallel meetings in conjunction with the EAS General Assembly (Prague, 1999). Helps organize graduate student mobility and summer schools.

- Atomic and Molecular Physics (1268)

Chair: R. Morgenstern, KVI, Groningen Univ., Zernikelaan 25 , NL-9747 AA Groningen [ +31 (50) $3633564 / 3634003$ ] morgenstern@kvi.nl.

Board: N.O. Andersen Copenhagen), V. Aquilanti (Vice-Chair, Perugia), D. Charalambidis (Crete), G. Delgado-Barrio

Madrid), R.J. Donovan (Edinburgh), A. Dowek (Paris), G. Gerber (Würzburg), J.A.R. Griffith (Birmingham), V. Ivanov (St. Petersburg), R.C. Thompson (Treas., London), H. Winter (Vienna), J.A. Zakrzewski (Cracow).

Provides a forum for and represents European scientists interested in the physics of atoms, ions, molecules, and clusters, and their structure and spectra, their interactions with radiation and their interactions with other particles. Scope partially overlaps with those of QEOD and PPD. Conference: European Conference on Atomic and Molecular Phy sics (ECAMP; triennial; July 1998, Sienna). ECAMP has strong links to physical chemistry through a Chemical Physics Symposium that was sponsored by the Faraday Society, the Deutsche BunsenGesellschaft and the Soçiété Francaise de Chimie at ECAMP-5.

Chemical Physics Section (522) - Chair: G. Delgado-Barrio (Madrid). Organizes a special symposium at ECAMP.

Electronic and Atomic Collisions Section (388) - Chair: N.0. Andersen (Copenhagen). Conference: European Sectional Conference on the Atomic and Molecular Physics of Ionized Gases (ESCAMPIG; biennial; 250; 14th; 25-28 August 1998, Mamahide, Ireland; 600 part.). Helps organize the International Conference on the Physics of Electronic and Atomic Collisions (ICPEAC; biennial; 23 - 29 July 1997, Vienna). Organizes the European Research Conference on Particle-Solid Interactions.

European Group of Atomic Spectroscopy (EGAS; 417; http://www.ulg.ac.be/ipne/data/egas/egas.html) Chair: J.A.R. Griffith (Birmingham). Conference: EGAS conference (annual; 250; EGAS-29; 15 - 18 July 1997, Berlin).

Molecular Physics Section (485) - Chair: R.J. Donovan (Edinburgh). Helps organize the international conference on the dynamics of molecules (Molec).

\section{- Condensed Matter Division (CMD; 2561)}

Chair: P. Wyder, Laboratoire des Champs Magnétiques Intenses, MPI-CNRS, BP 166X, F-38042 Grenoble Cedex 9 [+33 (4) 76855601 / 76855610 ] wyder@polycnrs-gre.fr. Board: O.K. Andersen (Stuttgart), F.J. Baltá Calleja (Madrid), J.L. Beeby (Leicester), J.E. Enderby (Bristol), 0. Fischer (Geneva), J.J.M. Franse (Amsterdam), F. Gautier (Strasbourg), H.U. Habermeier (Strasbourg), K. Heremans (Leuven), S. Hess (Berlin), I. Ipatova (St. Petersburg), G. Martinez (Vice-Chair, Grenoble), V.V. Moshchalkov (Leuven), R.J. Nicholas (0xford), R.M. Pick (Paris), G.A. Sawatzky (Groningen), K. Wandelt (Bonn), A. Zawadowski (Budapest).

A confederation of several specialized Sections with additional Divisional activities such as coordinating the Sections and promoting condensed matter research in Europe \& organizing conferences not covered by a Section. Conference: General Con- 
ference of the Condensed Matter Division of EPS (annual; 800 participants when held separately; held every three years in conjunction with the condensed matter general meeting of either the French Physical Society, the German Physical Society or the UK Institute of Physics; 22-28 August 1997, Leuven). Collaborates in the scientific programme of the European Materials Research Society annual conference.

Liquids Section (347) - Chair: L. Reatto (Milan). Conference: Liquid Matter Conference (triennial; 1999; 300 part.). Organizes topical workshops.

Low Temperatures Section (636) - Chair: V.V. Moshchalkov (Leuven).

Macromolecular Physics Section (406) - Chair: F.J. Baltá Calleja (Madrid). Organizes Europhysics conferences on a topical subject most years.

Magnetism Section (683) - Chair: J.J.M. Franse (Amsterdam). Helps organize the European Magnetic Materials and Applications Conference (EMMA; Sept. 1998, Zaragoza; 400 part.)

Metals Section (712) - Chair: E. Gautier (Strasbourg). Proposes speakers for the Division general conference.

Semiconductors Section (1128) - Chair: R.J. Nicholas (Oxford). Promotes and sponsors an annual Erice school on semiconductor physics.

Surfaces and Interfaces Section (1184) - Chair: K. Wandelt (Bonn). Conference: European Conference on Surface Science (ECOSS; annual; Sept. 1997, Twente)

- High Energy and Particle Physics Division (831)

Chair: G. Jarlskog, Physics Dept., Lund Univ., Sölvegatan 14, S-223 62 Lund [ +46 (46) 222 94 50/222 47 09] goran@hplund1.cern.ch.

Board: J.J. Aubert (Marseilles), M. Baldo-Ceolin (Padua), F. Barreiro (Madrid), F.A. Berends (Leiden), Ch. Berger (Aachen), A. Bialas (Cracow), M. Davier (Paris), L. Evans (Geneva), M. Greco (Frascati), P. Kalmus (London), W. Kummer (Sec., Vienna), J. Lemonne (Brussels), G. Mikenberg (Geneva), J. Niederle (Prague), R. Orava (Helsinki), J. Pisut (Bratislava), G. Ross (Oxford), J. Wess (Munich), P.M. Zerwas (Hamburg).

Coordinates views on research facilities, organizes conferences including topical meetings and assists in the coordination of advanced educa-tion in the theoretical and experimental physics of elementary particles and fundamental interactions. Collaborates with ECFA, NuPECC and ICFA. Conference: Europhysics International High-Energy and Particle Physics Conference (biennial; 19 - 26 Aug. 1997, Jerusalem ; 700 part.). Awards: High Energy and Particle Physics Prize (biennial; awarded at the HEP conference).

\section{- Nuclear Physics Division (703)}

Chair: R.A. Ricci, Lab. Nazionali de Legnaro (INFN), Via Romea 4, I-35020 Legnaro PD [+39 (49) $8068313 / 641925$ ] raricci@clulnl.Inl.infn.it

Board: A. Bertin (Sec., Bologna), J. Durell (Manchester), I. Lovas (Budapes), G.C. Morrison (Birmingham), Yu. Oganessian (Dubna), Z. Pluhar (Heidelberg), S.G. Rohozinski (Warsaw), L. Schaller (Fribourg), B. Schröder (Lund), A. van der Woude (Groningen), J. Vervier (Louvain), B. Vignon (Grenoble), W. Von Oertzen (Berlin).

Acts as a pole for promoting and rationalising scientific aspects of nuclear physics which are of interest to Europe's nuclear physics community. Aims to rationalise conferences. Collaborates with NuPECC. Conference: European Nuclear Physics Conference (annual; Sept./Oct. 1997, Italy; 400 part.). Organizes the European Research Conference on Nuclear Physics. Collaborates with NuPECC on the Editorial Board of Nuclear Physics International.

\section{- Plasma Physics Division (493)}

Chair: F.W. Sluijter, Dept. of Applied Physics, Univ. of Technology, Postbus 513, NL-5600 MB Eindhoven [+31(40)2474288/2445253] ria@vsrs.ni.phys.tue.nl Board: C. Alejaldre (Madrid), F. Alladio (Frascati), J.S. Bakos (Vice-Chair, Budapest), C.G. Falthammar (Stockholm), V.E. Golant (St. Petersburg), D. Grésillon (Palaiseau), J. Hugill (Manchester), R. Koch (Jülich), D. Laurent (St.Paul Lez Durance), M. Liberman (Uppsala), E. Manso (Lisbon), S. Prager (Madison, USA), U. Schumacher (Stuttgart), M. Siegrist (Lausanne), P. Sunka (Prague), F. Wagner (Garching), H. Winter (Vienna).

Unites European scientists interested in the physics of fully and partially ionized gases. Aims to promote research and teaching in plasma physics and its applications, to facilitate research collaboration and to represent European physicists outside Europe. Coordinates activities with the American Physical Society. Collaborates on the Editorial Board of Plasma Physics and Controlled Fusion. Conference: European Conference on Plasma Physics (annual; 9 - 16 June 1997; Berchdesgarden; 600 part.) that emphasizes fusion and non-fusion topics on alternate years. Collaborates in organizing the International Conference on the Phenomena in Ionized Gases (ICPIG; biennial; $17-$ 22 July 1997; Toulouse; 500 part.) and the International Conference on Plasma Physics (ICPP; biennial; June/July 1998, Kiev; 600 part.).

- Quantum Electronics and Optics Division (884) Chair: M. Ducloy, Lab. de Physique des Lasers, Institut Galilée, Univ. Paris-Nord, Ave. J.B. Clément, F-93430
Villetaneuse [ +33 (1) $49403900 / 49403200$ ] ducloy@|pl.univ-paris13.fr

Board: J. Balmer (Bern), Z. Bor (Szeged), R. Corbalán (Barcelona), T. Elsaesser (Berlin), W. Ertmer (Hannover), C. Fotakis (Crete), E. Giacobino (Paris), D.R. Hall (Edinburgh),D.C. Hanna (Southampton), G. Huber (Hamburg), J.-P. Huignard (Orsay), M. Inguscio (Florence), U. Keller (Zurich), T.A. King (Manchester), N.I. Koroteev (Moscow), A. Kujawski (Warsaw), L.A. Lugiato (Sec., Milan), J. Mlynek (Constance), G. Nienhuis (Leiden), 0. Poulsen (Copenhagen), Y. Prior (Rehovot), S. Svanberg (Lund), 0. Svelto (Milan), R.C. Thompson (London), L. Thylen (Stockholm), C. Webb (Oxford), H. Welling (Hannover), A. Zeilinger (Innsbruck).

Aims to act as a point of reference for activities in quantum electronics, optical physics and optics by coordinating conferences and other meetings and by fostering relations and the exchange of scientists. Conference: European Quantum Electronics Conference (EQEC; biennial; held with the Conference on Lasers and Electro-Optics/Europe; 7-11 September 1998, Glasgow; 1400 part.) in colla-boration with the Optical Society of America and the Laser and Electro-Optics Society. Organizes the European Research Conference on Quantum Optics. Collaborates with the International Council of Quantum Electronics in organizing the International Conference on Quantum Electronics and organizes Topical Meetings at the Munich Laser exhibition (16-20 June 1997). Publishes a Newsletter in Optics Communications (available by email and on EurophysNet) and Who's Who in Quantum Electronics. Awards: Quantum Electronics Prize (biennial; awarded at CLEO-Europe-EQEC).
Economy - Energy - Entropy An analysis of the economic, social and physics aspect that must be taken into account when considering energy production and consumption. Proceedings of the Europhysics Study Conference Economy - Energy - Entropy (CERN, Geneva; 11 - 13 May 1996) organized by the EPS Action Committee for Physics and Society. Published by the European Physical Society.

Editor: E.W.A. Lingeman (12 contributions; 170 pp.; SFR 40.-)

Orders: EPS, BP 69, CH-1213 Petit-Lancy 2, Geneva - Tel.: +41-22-7931130 - Fax: +41227931317 email: eps@cern.ch

The Global Warming Debate The Report of the European Science and Environment Forum. Gives additional background material to the discussion [see Europhysics News 27 (1996) 106 - 107] on global warming presented at the Europhysics Study Conference Energy - Economy - Entropy (CERN; 11 - 13 May 1996). Editor: J. Emsley (300 pp.; $\$ 25$.$) .$

Orders: ESEF, 73 McCarthy Court, Banbury St., London SW11 3RT, UK

\section{Special Rates for Computers in Physics}

Following an agreement with the EPS Computational Physics Group (CPG) - the EPS Interdivisional Group for Computational Physics - the American Institute of Physics (AIP) has announced that it is to reduce the annual subscription rate to its bimonthly Computers in Physics by $12 \%$ (to $\$ 52.75$ ) for renewing individual subscribers who belong to the CPG. Individuals currently receiving Computers in Physics will need to write "EPS subscriber" on their renewal invoices to qualify for this price reduction. In addition, there is a fixed $\$ 20.00$ surcharge for delivery by air freight to European addresses.

The AIP is also offering a special $25 \%$ reduction for first-time EPS subscribers, resulting in an introductory annual subscription rate of just $\$ 44.95$. The introductory rate provides a means for first-time subscribers to "try out" the publication while making less of a monetary commitment.

Qualifying physicists for the $12 \%$ and $25 \%$ price reductions include both Individual Ordinary Members of EPS as well as National Society Members (members of national physical societies) who have joined the CPG by notifying a national society. These price reductions are therefore potentially a special EPS benefit for all European physicists. The AIP will not raise the price of individual subscriptions to Computers in Physics in 1997. If price rises occur subsequently, EPS subscribers will still qualify for the $12 \%$ and $25 \%$ price reductions as described.

If you are interested in subscribing to Computers in Physics, please contact: Circulation Dept., AIP, 500 Sunnyside Blvd., Woodbury, NY 11797, USA (tel.: +1-516-576 22 30; fax: +1516-576 24 81; http://www.aip.org/cip/ciphome.html). 


\section{Statement}

EPS High Energy and Particle Physics Division has issued the following statement in the light of indications that Germany and other CERN Member States wish to reduce their CERN contributions from next year [see EN 27 (1997) 198].

The Board of the EPS High Energy and Particle Physics (HEPP) Division expresses its satisfaction that the Member States of CERN unanimously support the Large Hadron Collider programme and wishes that the project be completed in a singles step.

Nevertheless, we are very concerned with the dramatic changes proposed at rather short notice for the budget of CERN. We strongly hope that the CERN Council during it next meeting in December will agree to long-term budgetary measures which will allow CERN to complete the $\mathrm{LHC}$ in the foreseen timescale in a safe an responsible manner, and without reducing drastically the general support of the overall scientific programme of CERN which makes use of unique frontline facilities, such as LEP, in which the Member States have invested heavily.

\section{G. Jarlskog, Chairman, EPS HEPP Board}

\section{European Physicist}

The Register Commission for the designation European Physicist (Eur Phys) meeting in Geneva on October agreed to admit 14 applicants to the European Register of Physicists, subject to completion of the normal requirements. This means that a total of 46 applicants have qualified to become European Physicists since the Eur Phys scheme was launched last year.

The Commission is presently looking at ways to enhance the status of the Eur Phys designation through measures such as trademark protection and European Union recognition. A determined effort is also being made to establish regular and effective communication with the European Physicists via Europhysics News (which each receives for one year free-of-charge ) and via a WWW page at http://epswww.epfl.ch/eurphys/.

\section{Errata}

F.D. Santos, the author of Major Investments, with Changes to Come [EN 27 (1996) 108] wishes to point out that the introduction to the section Physics in Portugal on page 109 omitted a reference to the small but active research group at the University of Minho. The Editor apologises for this omission.

P. Inia [EN 27 (1996) 158] is with the Clinical Physics Department, Medical Centre Leeuwarden, and not with the Katholieke Universiteit Leuven. The Editor apologizes for this mistake.

\section{Divisional Conference Reports}

The November - December 1996 issue of Europhysics News includes reports of: - European Particle Accelerator Conference (EPAC'96), Sitges: EN 27 (1996) 220. - 1996 Conference on Electro-Optics/Europe (CLEO/Europe - EQEC'96), Hamburg: EN 27 (1996) 223.

\section{Conferences and Schools}

Europhysics News maintains the Europhysics Meetings Database of physics events worldwide of interest to events to the EPS Secretariat. The meetings listed below are in two sections. The first gives conferences, workshops, schools, etc. that are organized or sponsored by EPS (the sponsored events are indented). The list continues in Europhysics News with a selection, taken from the database, of the most important conferences. The

\section{- 1997 EPS ORGANIZED \& SPONSORED}

-April 5-8 Structure-Physical Properties Relationship of Block Polymers - Thermoplastic Elastomers: 4 th Int. Symp./ Europhysics Conf. on Macromolecular Physics Szczecin, PL Z. Rostaniec, TU, Al. Plastów 17, PL-70-310 Szczècin

$+48(91) 494852 / 340558$

- May11 - 22 Spin in Gravity - Is it Possible to Give an Experi mental Basis to Torsion ?: Int. School of Cosmology and Gravitation-15th Course Erice, $1 \quad c$ Erice - May 26 - 30 Solar Cells: A New Challenge for the Mediterranean Area - Physics of Mater. for Solar-Energy Conversion Univ. de Paris-Sud, Bât. 213, F-91045 Orsay Cedex + 33 (1) 69157468/69156777 annick@scipion.ppm.u-psud.fr - June 1- 6 Surfaces and Interfaces in Polymers and Composites: Europhysics Conf. on Macromolecular Physics Lausanne, $\mathrm{CH} \quad$ J.-A.E. Mânson, EPFL-DMX, CH-1015 Lausanne +41 (21)69348 48/6935880 eps97@dmx.epfl.ch http://sdmac6.epfl.ch/EPS97/home.html

June 4- 6 Physics Teaching in Engineering Education: ist European Conf. (PTEE) Copenhagen, DK E. Oehlenschlaeger, Engng. Coll., Lautrupvang 15, DK-2750 - June 6-11 Fundamental Aspects of Surface Science -

Surface Physics with Synchroton Radiation: ERC in Physics Castelvecchio Pascoli, 1

c: ERC

- June 9-16 Controlled Fusion and Plasma Physics: 24th European Conf. Berchdesgarden, D J.Hofmann, MPI f. Plasmaphysik, Postfach 1533, D-85748 Garching

+ 49 (89) $32994154 / 32994313$ hofmann@ipp-garching. http://mpg.dehttp://www.ipp.mpg.de/E3/EPS_1997.html - June 16 - 20 Adaptive Optics: Laser 1998 Topical Conf Munich, D F. Merkle, Zeiss Jena GmbH, Tatzen-promenade 1a, D-07740 Jena + 49(3641)64014/642454 http://www.messe.muenchen.de

- June 16 -20 J Novel Laser Devices: Laser 1998 Topical Conf. Munich, D G. Leuchs, Physics Inst., Erlangen Univ.

Standstr. 7, B2, D-91058 http://www.messe.muenchen.de Experimental Physics: 8th Marcel Grossman Meeting Jerusalem, IL T. Piron, Racah Inst. of Physics, Hebrew Univ., IL-91904 Jerusalem +972 (2) $658423 /$ (2) 611519 tsvi@shemesh.fiz.huji.ac.il

- June 30-July 11 Science and Technology of Magnetic Films and Nanostructures: 3 rd EPS Southern European School of Physics Porto, P J. Bessa Sousa, Physics Dept., Porto Univ., R. do Campo Alergre 687, P-4150 Porto +351 (2) $6082642 / 6082679 \quad$ bsousa@fisi.fc.up.pt - July 8 -9 The Beginnings of Radioactivity - Astonishments, Contradictions Applications: EPS History of Physics Interdivsional Group Conference

Paris, $\mathrm{F}$ European physicists. Organizers should send details of Portici, I A. Suzor-Weiner, Lab. de Photophys. Moléculaire, Ballerup + 45(-) 44978088/44972700 lop@cph.ih.dk June $22-27$ Recent Developments in Theoretical and

database is available in a searchable form on the EPS EurophysNet World-Wide Web information service at http://epswww.epfl.ch/conf/ with a list of pointers to meetings lists at http://epswww.epfl.ch/conf/urls.html. TIPTOP at http://www.tp.umu.se/TIPTOP/ provides the official upload facility for the database. Meetings announced via TIPTOP are entered into the database. c: contact for European Research Conferences in Physics, + country code (city code) tel. no. / fax no.

C. Blondel, CRHST, Cité des Sciences et de l'Industrie, F-75930 Paris Cedex +33 (1) $40057000 / 40057921$ July $12-17$ Bose-Einstein Condensation in Atomic Vapours: ERC in Physics Castelvecchio Pascoli, I c: ERC - July 15-18 European Group for Atomic Spectroscopy: 29th Ann. Conf. (EGAS-29) Berlin, D H.-D. Kronfeldt, Otisches Inst., TU Berlin, Hardenbergstr. 36, D-1063 Berlin $+49(30) 31424807 / 31422742 \quad$ kf@mail.physik. tu-berlin.de http://www.ulg.ac.be/ipne/data/egas/egas.html - July $17-22$ Phenomena in Ionized Gases: Int. Conf. Toulouse, F M.C. Bordage, CPAT, Univ. P. Sabatier, 118, rte. de Narbonne, F-31062 Toulouse + +33(5)61558680/ $61556332 \quad$ icpig@cpa22.ups-tlse.fr icpig97.ups-tlse.fr -Aug. 19-26 High Energy Physics: Int. Europhysics Conf. (HEP '97) Jerusalem, IL E. Rabinovici, Racah Inst., Hebrew Univ., IL-91904 Jerusalem + +972(2) 6584550 I 6584437 lev@vms.huji.ac.il

-Aug. 24-30 Advanced Quantum Field Theory: ERC in Physics La Londe les Maures, $\mathrm{F} \quad c$ ERC -Aug. 25-28 Physics Computing '97: 9 th Joint EPS/APS Int. Conf. on Physics Computing (PC'97) Santa Cruz, CA, USA B.M. Klein, Physics Dept., Univ. of California, Davis, CA $95616-8677$, USA +1 (916) $7525989 / 7524717$ klein@bethe.ucdavis.edu

- Aug. 25 - 28 Condensed Matter Division of EPS: 16 th General Conf. Leuven, B CMD16, Dept. Natuurkunde, KUL, Celestijnenlaan 200, B-3001 Leuven + 32 (16) $327175 / 1327983 \quad$ cmd.16@fys.kuleuven.be - Sept. Surface Science: 17 th European Conf. (ECOSS-17) Twente, NL

- Sept. 13-18 Quantum Optics: ERC in Physics

Castelvecchio Pascoli, F

Sept. 16-24 Int. School in NuclearPhysics - 19th Course: Neutrinos in Astro-, Particle and Nuclear Physics Erice, I A. Fässler, Theo. Physics Inst., Tübingen Univ., Auf der Morgenstelle 14, D-72076 Tübingen 1 + 49 (7071) 296370 I $296400 \quad$ amand.faessler@uni-tuebingen.de - Sept. 21 - 25 Dynamical Props. of Solids: ERC in Physics Villigen, $\mathrm{CH}$ c: $\mathrm{ERC}$

- Sept. 23 - 28 Particle-Solid Interactions - Strong Perturbations: ERC in Physics San Sebastian, E c: ERC

- Oct. Electromagnetic Structure of Hadrons and Nuclei: ERC in Physics Santorini, GR $c$ ERC Oct. 7-11 Advanced Technology and Particle Physics: sth Int. Conf. Como, I P.G. Rancoita, INFN, Physics Dept., Via Celoria, 16, 1-20133 Milan + 39 (2) 2392331 / 2392617

Nov, 3- 7 Accelerator \& Large Experimental Physics Control Systems: Int. Conf. (ICALEPCS '97) Beijing, China R. Hou, High Energy Physics Inst., POB 918, PRC-100039 Beijing + 41(10) 68219643 / 68213374 icalepcs@sun.ihep. ac.cn http://ecpcowww.cern.ch/ICALEPCS/index.html

\section{Addresses}

AAS: Amer. Astro. Soc., 1630 Conn Ave NW, Suite 200, Washing ton DC 20009, USA +1 (202) $4626903 \%$ - www.aas.org APS: Amer. Phys, Soc., ACP, 1 Physics Ellipse, College Park, MD20740-3844, USA + meetings@aps.org $+1(301) 2093090 / 2090844$ Www.aps.org Strasbourg Cedex euresco@esf.org $+33(-) 88767135 / 88366987$ (CSEM, Via Guarnotta, 26, 1-91016 Erice +39(923) 86 $9133 / 869226$ hq@ccsem.ccsem.infn.it www.ccsem.infn.it GPS: German Phys. Soc., Haupstr. 5, D-53604 Bad Honnef +49 (2224) $92320 / 923250$ snhonnef1 pbh-uni-bonn.d ICTP: Int. Centre for Theo. Physics, POB 586, 1-34100 Trieste +39 (40) $22401 / 224163$ bowman@ictp.trieste.it www ictp trieste.it

IEE: Inst. of Electrical Engineers, Savoy Place, London
WC2R OBL, UK

+44 (171) $3445478 / 2408830$ conference@iee.org.uk www.iee.org.uk IEEE: Inst. of Electrical \& Electronic Engineers, 345 E 47 th St.

New York, NY 10017, USA member.services@ieee.or +1 (212) $7057900 /$

. +44 (171) $4704800 / 4704848$ physics@iop.org www.iop.org

LEOS: IEEE/Laser \& Electro-Optics Soc., 445 Hoes Lane, POB 1331. Piscataway, NJ 08855-1331, USA +1 (908) 5623893 5621571 m.estrin@ieee.org strauss.msrc.wvu.edu/leos/ MRS: Materials Res. Soc., 9800 McKnight Rd., Pittsburg, PA 15237, USA +1(412) $3673003 / 3674373$ info@mrs.org dns.mis.org

OSA: Optical Soc. of Amer., 2010 Mass. Ave. NW, Washington, DC 20036-1023, USA +1(202) $2238130 / 2236100$ info@osa.org 